\title{
Online Training for Working with Student Veterans: A Social Work Elective Course
}

\author{
Katherine Selber, Mary Jo Garcia Biggs, Nancy Feyl Chavkin, and Micah C. Wright \\ Texas State University
}

\begin{abstract}
This article describes one school of social work's innovative online elective course to prepare Masters of Social Work (MSW) students for practice with the military, veterans and their families. Developed as part of a university-wide Veterans Initiative, this online course keeps the focus on the student veteran and uses the best practices of online education. The authors share their strategies and make recommendations for future trainings.
\end{abstract}

\section{Introduction}

Veteran service organizations such as the Veterans Administration (VA), community-based agencies, higher education institutions, workforce and other governmental services report a growing demand for services to meet the needs of over 2.4 million military personnel who are transitioning into the community after over a decade of war (Dao, 2012; Franklin, 2009; Selber, in press). Part of this challenge is increasing the number of culturally competent veteran service providers who can care for this population (Coll \& Weiss, 2013; Luby, 2012; Newell, 2012). Social work education has been slow to respond to the need to serve military, veterans and their families during the recent wars and this slow response has produced calls for action that have resulted in a list of advanced practice standards for military social work to guide educational and training efforts (Council on Social Work Education, 2010; Rubin, 2012). In addition, some schools of social work have added coursework and content to address the complex needs of this population (Newell, 2012; Petrovich, 2012; Rubin, 2012; Savitsky, Illingworth, \& DuLaney, 2009; Whitworth, Herzog, \& Scott, 2012). However, much more work is needed to develop curriculum content to help meet this educational challenge (Johnson \& Johnson, 2013). This call to action for social work education has coincided with the recent emphasis on and growth of online training opportunities in social work education (Council on Social Work Education, 2011, 2012; East, LaMendola \& Alter, 2014). Although online education has increased dramatically in the last 10 years, including in social work education, research on its efficacy and outcomes is still needed to examine and enhance its applications (Abels, 2005; Allen \& Seaman, 2014; Lawrence \& Abel, 2014). Indeed, the nexus of supporting online training innovations and serving veterans presents social work education with unique opportunities to contribute given that social work is a primary provider of veterans' services within the Veterans Administration and in the mental health fields. 
This article reports on an effort by one school of social work to prepare Masters of Social Work (MSW) students for practice with the military, veterans and their families through developing classroom and field content to train social workers to work with this population. The article describes an online version of a social work elective course developed and taught over the past two years. The course forms part of an overall service and training model, the Veterans Initiative, for working with student veterans on campus and that context will also be outlined because it provides the overarching framework and helps define the long-term goals for the course. The article describes lessons learned: outcomes associated with the social work course and suggested recommendations for online efforts for social work education and practice with veterans.

\section{Background}

The course described in this article forms part of a multiyear effort to work with student veterans at a four-year Texas university that has an enrollment of over 36,000 students with 2,800 student veterans and dependents. The campus is located in a military corridor that has over 70,000 military families living in it and many are Iraq and/or Afghanistan veterans, including a large population of Guard and Reserve.

In 2008, to respond to the challenges presented by increased enrollments of student veterans on campus, the primary author, a faculty member at the School of Social Work, provided leadership to develop a Veterans Advisory Council. This council has met monthly and is made up of 15 staff and faculty from a cross section of administrative units on campus with a mission to identify needs, enhance services and support student veteran graduation. During the past six years the Veterans Initiative model has been developed to meet the needs of our student veterans and has gained recognition nationally as the 14th-ranked four-year university for veteran-friendly practices (Military Times Edge, 2014). The model encompasses services across an array of areas and challenges common to the student services field. Based on the original psychosocial adult development theories of Schlossberg, Waters, and Goodman (1995) and adapted by DiRamio and colleagues (Diramio, Ackerman, \& Mitchell, 2008, 2009), the model depicts the needs of student veterans for information and psychosocial education as they transition into, through and out of their roles on campus. In addition, the individual student veteran is viewed from a strengthsbased, holistic perspective that acknowledges the importance of their prior military experience, health and behavioral health needs, family and financial needs and their academic and career aspirations. The framework used for developing services includes a transitional, veteran-centered approach and is grounded in active outreach to the student veteran population using a peer-to-peer approach. Services included in the Veterans Initiative consist of academic support; health and behavioral health; career and leadership; and training, technical assistance, and research. These services are provided by the efforts of a team of faculty and staff from a number of administrative units and departments on campus including the following: Student Affairs, Diversity and Inclusion, Social Work, Veterans Affairs Office, Counseling Center, Admissions, Graduate College, Career Services, Writing Center and Tutoring Center.

In order to blend service delivery and training missions, in 2010 we decided to add to the model a faculty-supervised field unit of Bachelor of Social Work (BSW) and MSW student interns on campus that trains and provides services within the program's structure. Interns perform the following functions: outreach; case management, including brief assessment, linkage, and referral; and program development and research functions. They also assist in developing service initiatives, such as running fundraising events, organizing outreach events and helping develop partnerships and new program activities. This field unit has also contributed to the training of MSW students who are part of a three-year, 2012-2015 federal training grant from the Health Services Resources Administration (HRSA) to provide competitive training stipends to MSW trainees who commit to working with military personnel, veterans and their families after graduation. The HRSA grant, "Project Stand Up for Veterans," has proven to be a successful initiative. Of the 17 current graduates, all have taken the social work elective, and 15 of the 17 are working in the field of military social work. 
As part of the training aspect of the Veterans Initiative model and with the increased interest from the HRSA grant, the School of Social Work decided to develop an online version of the campus-based graduate level course used for preparing students to work with veterans. This course is organized as an online social work elective and is the primary focus of this article.

\section{Setting}

The School of Social Work at Texas State University has developed an innovative distance education MSW degree program to help rural military students-including veterans, active-duty, reservists, National Guard, military spouses, and family members of each of these groups-achieve a degree that allows them to staff and lead vital agencies in underserved areas. Over the past five years, approximately $7 \%$ of our school's MSW students are veterans or their family members and $8 \%$ of our BSW students are veterans or their family members.

Our MSW students have traditionally pursued the MSW, a mainstay in mental health fields, through face-to-face, on-campus classes. However, since 2003 we have pursued a rigorous process of development for our online program. Our online MSW program has mirrored the history of online education in social work education by first sending faculty to off-site locations, then implementing videoconferencing (ITV) efforts, and now using web-based methods (East, LaMendola, \& Alter, 2014). This push for online education on our campus is due in large part to the fact that Texas is geographically expansive and culturally diverse, with many pockets of rural areas that are far from large cities. Because the state is vast and deployments happen often, many students cannot easily commute to a university. This expansiveness is highlighted by the fact that driving straight across Texas from east to west covers 762 miles.

Educational services in Texas must take into account the state's demographics. Texas has over 1.6 million veterans, ranking second nationally. The central Texas corridor that the campus serves is home to over 285,000 veterans, many of them Iraq and Afghanistan veterans (U.S. Department of Veterans Affairs, 2014). Likewise, about 1 million veterans are within the Veterans Administration's 17 VISN care region, which includes the corridor that serves our campus. The university serves a diverse group of both rural and metropolitan students and is a national leader in graduating Hispanic students. The university is now a federally designated Hispanic Serving Institution (HSI) with over 31\% of the student population being Hispanic.

Our School of Social Work maintains a mission to prepare students for public service, especially for people who are disadvantaged and often forgotten. Our distance education efforts have encompassed several phases and have evolved over time primarily responding to diverse community stakeholder requests for MSW education. Initially distance education was a partnership with a small campus, University of Houston-Victoria, located about 100 miles from our campus. Sharing faculty and supplying curriculum from 2000-2007, our faculty commuted to teach courses and occasionally offered courses via ITV technology. In 2003, the school received a federal grant from the Administration for Children and Families, Children's Bureau, which allowed the school to translate its MSW curriculum to an entirely online format. With this funding the school offered the MSW degree part-time online to around 20 Child Protective Services (CPS) employees in rural Texas. Students completed field placement in their home communities under the supervision of experienced licensed MSWs, with oversight visits from the faculty. In 2005 the school's online efforts further evolved, using hybrid methods of face-to-face and online teaching at our Round Rock campus 50 miles north of our main campus. The town, located in Williamson County, is a gateway to a large rural population to the north with many military families, including Ft. Hood.

Online instruction methods also advanced during the growth. As our online program expanded, teaching methods became more diverse. The university's teaching platform allowed students to participate in discussion boards, chat rooms, virtual group meetings, blogs, instructor-student conferencing, and consultation. Faculty increasingly enriched curriculum by providing real-time, camera- 
and-microphone-assisted instruction, extensive supplementary reading material, video clips, filmed roleplaying, and connections to pertinent websites. Students were required to do cooperative work. Even though they lived many hundreds of miles apart, the students came to know each other very well through technology and their communication networks far exceeded the requirements of the program. Many of the students became friends, discussing work issues and learning from each other.

The university was supportive of the online program and continues to strongly support it because of its potential to meet the mission of serving multiple underserved student populations such as veterans. In fact, the university has expanded the online MSW degree program and funds it internally. Many of our online students have been involved with active-duty deployments overseas, are reservists who are activated for military service, or are military service family members traveling from one duty station to another. Because the university has made a commitment to enhance programming and supportive services in general for veterans, this population has been recruited as well for the online MSW program.

Our school continues to cooperate closely with the university's Instructional Technology unit and works with professional course programmers to create lively, varied, well-integrated online courses that involve a good deal of real-time interaction via cameras and microphones. The Instructional Technology Support unit provides leadership and support for all phases of the design, development, and deployment of courses. The process involves instructional designers, classroom technology support, graphic artists, videographers, and computer programmers.

The first semester of development of a new course involves an in-depth design analysis, an overview of content, objectives and outcomes. The second semester involves the development phase, in which the course is built in a module-based format. The final semester involves the delivery of the course or the implementation phase, which ends with an evaluation using a student perception survey, with changes and edits implemented prior to the next offering. The school gives faculty members one to two semesters of course release to develop an online course before delivering it. Though course development is an expensive process, it is important to the university.

Consistent with the Online Learning Consortium's five pillars of quality of online learning, the university offers many opportunities for faculty development, including workshops on creating and teaching an online course, assessment of student learning, student learning styles and instructional design models. Certification is highly encouraged, and the university will pay the certification fees for faculty members who complete the rigorous training. The university utilizes the Quality Scorecard for Online Programs to consistently evaluate and determine the strengths and weaknesses of its programs in an effort to consistently improve and strategically plan for changes and trends. Blending the training and service missions for our student veterans through online courses has enjoyed a high level of support within the university.

\section{Investigation and Practice}

Creating the knowledge and skills needed to work with military personnel, veterans, and their families is a challenge for social work education. The emerging literature in social work and other helping professions describes the importance of establishing the cultural competence needed to work with this population (Coll \& Weiss, 2013; Demers, 2011; Forgey \& Young, 2014; Johnson \& Johnson, 2013). Cultural competence to work with military personnel, veterans and their families is essential because of the uniqueness of the military as a culture and its far-reaching impact on its members. Social workers must understand the special needs that result from high-risk training and service duties. Designing and teaching course content on the uniqueness of the military culture, including both its stressors and positive elements, is essential for preparing MSWs to be ready to work with veterans both in field internships and in employment settings.

The online social work elective course, Helping Veterans Transition, is designed as one tool for educating social work students for working with the military, veterans and their families. The course is 
the core of training in the Veterans Initiative model. The on-campus version of the course has been offered each semester for the past four years with the pilot online version added in 2012. One of the most important aims of the course is student engagement with the veteran population. Students are not just reading about veterans but also engaging with student veterans from campus and from the community where the student is enrolled. The following sections further describe the online course.

\section{Course Logistics}

The online version of the Helping Veterans Transition course has been offered three times on campus since 2012 and has trained over 70 students. Enrollments have ranged from 10 to 23 students each semester with all of those being graduate enrollment, most of which is in social work. Both direct practice and administrative leadership concentration MSW students may take the course as an elective. The course is mandatory if a student is interested in applying for the HRSA traineeship stipend.

\section{Course Demographics}

Over the past two years of online course offerings, the following demographics have been collected using the information form completed by students on the first day of class: Students are all MSW or graduate students from other departments. Approximately $10 \%$ of the students are from other departments, and $90 \%$ of those are from social work. Some of the other academic programs represented by enrolled students are therapeutic recreational sports, education and student affairs and leadership studies. Approximately $12 \%$ of the class members have been veterans, and about $30 \%$ have some affiliation with the military, such as being military family members, spouses, or significant others. In addition, all students stated they were motivated to take the course because they either wanted to work with veterans post graduation or wanted an internship with the population.

\section{Course Objectives and Content}

The objectives of the course are designed to cover an array of information on veteran's services and military social work. These include learning about military culture: the transitional challenges of military personnel; the needs of a range of special populations, such as student veterans, women, and military widows; treatment issues, such as post-traumatic stress; and systems of care and policies involved with providing services. Readings in the course are divided between books containing firsthand accounts of veterans' experiences and perspectives and academic journal articles that report on research and best practices. Web-based links to systems of care and practice content, webinars, and videos are used extensively as well. Providing digitized versions of speeches given by guest speakers from the community at the campus-based version of the course is also an important part of keeping the online class current.

\section{Course Methodologies}

A number of methodologies are used in this online format, including videos of instructor lectures, digitized lectures from guest speakers from the practice community, discussion forums and learning activities such as matching terms and definitions. Documentaries from various sources and video clips from movies and popular culture are also used. We use online resources that bring practice cases and practice experiences into focus, especially with Adobe Connect and Camtasia Relay.

\section{Course Assignments}

The course has a core assignment that includes interviewing a veteran, with preference given to student veterans affiliated with either our campus or a campus in the community where the enrolled student lives. The aim of the assignment is to give hands-on experience of gathering information on the student veteran's transition into and through the university. Attendance at three veteran events of the student's choice is required so that the student is further exposed to military culture and the unique needs of the population. Online objective tests that cover readings and class materials are also given.

One of the assignments that consistently receives positive reviews is the service-learning project. Team-based veteran service projects provide hands-on service learning experiences; all of the service- 
learning projects focus on helping veterans and families. The service-learning project is coupled with a literature review that is related to the project. The project provides more interaction with veterans, since the goal of the service-learning project is to assist veterans and their families within the enrolled student's community.

An excellent example of a service-learning project that has flourished on our campus and made a difference in the community is the partnership with the Campus Writing Center and its innovative Tutoring Corps for Veterans. The project was spearheaded by a veteran who was enrolled as a graduate student in the Masters of English curriculum and took the online course. His perspective on participation in the course is related below under “A Student Veteran's View." The veteran led a team of enrolled students in the course to support and develop a Writing Workshop for Veterans that focuses on therapeutic writing techniques to help soldiers work through issues such as PTSD and other everyday struggles veterans face, including lack of employment and social issues, following a return from active duty. The team planned and prepared materials for the Veterans Writing Workshop. The title of this writing workshop was Bringing Veterans Together to Heal. The goal was to design and develop a workshop that could support student veterans' healing and be a tool for teaching student veterans how to take care of themselves delivered in a format that is not associated with stigma among their peers. This educational approach helps eliminate the stigma about "being ill" and receiving help. Also, with the help of other veterans attending the workshop, support circles were developed, and strong friendship bonds were created. In vet-to-vet writing, veterans share and write together, so there is a reduced danger of isolation, and listening to the experiences of other veterans can help clarify feelings and emotions. Writing exercises were developed to use during the weekend workshop.

\section{Lessons Learned}

Below are accounts from a student veteran who took the course, class feedback and an instructor's retrospective.

\section{A Student Veteran's View}

In the summer of 2013, I took a class on-campus on transitioning of veterans into the community. It was a social work class that gave students who were interested in working with veterans a chance to not only learn the culture of the military but to also become more aware of the different struggles military service members endure when returning from overseas. I took the class not because I was interested in learning about the military culture-I had served four years in the Marine Corps and already felt accustomed to the ins and outs of military tradition-but to become more versed on the different perceptions of military issues and the various treatment options available.

At that point in my graduate education, I had already created a veteran-to-veteran tutoring program that helped veterans become more comfortable utilizing the academic services that were afforded to them on campus. I had been apprehensive to register for online classes in the past. Nevertheless, the online version of Helping Veterans Transition was the only one I could take due to scheduling conflicts with my degree. I could not take the class in person, and thus I somewhat reluctantly signed up for an online class. It felt very weird to not be sitting in a classroom, facing an instructor with a white board - this was a commonality in my military training and my education up until that point; however, as my first day of the class came to an end, I quickly realized that the only thing that this class was missing was a physically present instructor. The class was structured very similarly to any graduate course that would be offered in a face-to-face setting. There were lectures (recorded), an adequate amount of assigned readings - texts with topics ranging from veterans dealing with PTSD to service members coming home and coping with cultural differences-chances to discuss learning theories and complications, and assignments in the form of papers, online discussion forums, blogs, and reviews that had to be completed by a specific time and date. As far as the level of rigor in a classroom was concerned, 
this class certainly met my expectations of a graduate education. The only thing that I assumed was missing was the chance to collaborate with other students.

At the beginning of the semester, the professor had divided us into groups-these groups would be set for the semester, and each group would be responsible for completing assignments at the end of each module. The question for me remained, how would I be able to effectively collaborate with my group members? I saw a situation in which I would be doing the bulk of the work to avoid the complications of distance learning. I was wrong. My first group meeting was conducted over Adobe Connect; each team member discussed the different elements of the upcoming assignment and a future, larger, assignment. We figured out who was responsible for each element to be turned in, exchanged phone numbers, and went to work. During the course of the semester, my group exchanged over 30 e-mails and conducted countless over-the-phone and face-to-face meetings to complete assignments. At no point during the semester did my fear of a lack of collaboration become a reality.

In an online venue, collaboration and productivity are dependent on an individual's discipline at home. Although my fears, mostly about other people, told me that at-home discipline would be lacking, I was pleasantly surprised at the ability to work as a group and learn as a class. Helping Veterans Transition became an important part of my graduate education, and I am glad that I had the opportunity to take the course online. It was definitely a growth experience for me.

\section{Class Feedback on the Course}

To gain insight into the students' perspectives, we reviewed the course evaluations of two online sections of the class taught in 2013. There were a total of 34 students in the two sections (19 in one section and 15 in the other). The overall satisfaction with the course was 4.54 on a 5.0 scale. Using the same scale, students rated their learning in the course as a 4.63 and the assignments as a 4.86. In response to open-ended questions, students wrote the following: "I learned a multitude about U.S. troops and the difficulties they face when returning to civilian life"; "Guest speakers gave us great insight"; "Doing a project gave us hands on experience and it was an excellent teaching method"; "I loved this course"; "I learned a lot"; "I was able to speak to my newfound knowledge with veterans and civilians alike"; "I recommend that all students take this course"; and "It felt really good to have a chance to put together a project and give back."

In addition, we conducted a survey of the 34 students approximately a year after the course about what they had learned and its usefulness for their jobs and internships. The students who returned surveys ( $N=19$ ) identified the five curriculum topics where the most learning occurred: information about posttraumatic stress and mild traumatic brain injury; resources for helping veterans and families; issues that uniquely impact female veterans, such as military sexual trauma; and transitional issues related to leaving the military and returning to civilian life.

It was reaffirming to see that veterans and family members, although knowledgeable about military culture, still stated they had learned a lot in the course. For example, one veteran stated, "I feel a strong sense of loyalty to veterans. Being a twenty-year veteran I was surprised by the challenges our most recent veterans face.... I learned that I am not knowledgeable enough with the challenges recent veterans face." This veteran was open to learning about the new generation of veterans, and it was refreshing to hear that even a twenty-year retiree learned from the course. Students also mentioned that they appreciated the various guest speakers' expertise and that they enjoyed the range of topics addressed by these experts, especially the founder of the American Widow Project. Another veteran stated that the course had been "very beneficial to his understanding of the military community in general" and also expanded his knowledge of female veterans' issues. A military spouse stated that although she had felt prepared, she had quickly "realized her previous knowledge was limited." Another military spouse mentioned that knowledge gained from the workforce unit would be helpful to her family when her spouse retired from active duty. 
Many of the students provided positive feedback about their service-learning projects and stated that they learned from their team members and peers while in class and while working on these projects. Overall, students seemed to have positive feelings about the course and what it covered for preparing them for future practice. For example, one said, "Not only did it give me knowledge but as a result I have also adopted a sense of urgency in respect to learning more about effective treatments... and insights into military culture.”

\section{An Instructor's View}

The online version of the course has been taught for two years and some important lessons have been learned. First and foremost, the instructor for the course must have a background in veterans' issues so that credibility in cultural competence is evident. Veterans, family members, or those with extensive work experience with the population are options for the instructor role. Our online course is taught by an instructor who is a military family member with extensive experience working with student veterans on campus and has worked in the veteran community in the state.

Another important part of the instructor's role is managing the impact of sensitive content on issues such as death, combat and other factors that are part of the military culture. This task ensures a learning focus and not one based on excessive self-disclosure. This classroom management issue is more of a challenge online than on campus. As is often the case with online courses, discussion forums must be monitored daily to stay current with any sensitive topics. The need to be aware of these issues must be explicitly covered in the course outline, repeated at the beginning of each online discussion forum, and regularly monitored in the online discussion forums. The instructor should also address this topic in an online video at the beginning of the course. Including articles about ethical issues and the civilianmilitary divide can also help build sensitivity to these topics.

Videos of guest speakers from the community who have expertise in specific practice issues helps keep the content current. Guest speakers are very important to an online audience because they can cover a broad range of topics and maintain interest in the course. The instructor must have community connections and understand resources for the military, veterans, and military family members in order to enlist this type of participation and buy-in from the community. Teaching the class simultaneously on campus has facilitated access to this resource.

Community connections are also important for the service learning projects used as an assignment for the online course. These projects are tied to what is currently happening on campus for student veterans or in the veteran service community, wherever the enrolled student is located. The use of weekly progress reports facilitates tracking the progress of these service-learning projects. The instructor found that weekly Skype, Connect, or conference calls and e-mail reports facilitated the team process and helped keep the service-learning projects on track.

Having veterans in the course is also helpful and has thus far been a part of every online course offering. Although the professor usually knows who is a veteran if the veteran has disclosed this information to the instructor, other peers enrolled in the course may not know. The instructor leaves this disclosure to the veteran, and it is not required.

Two of the overall goals of the course are to encourage engagement with veterans as well as build a knowledge base through readings, course lectures, and other materials. The goal of engagement is more difficult in the online course. Telephone conference calls to review team projects, Adobe Connect sessions and the knowledge of service-learning opportunities in the community of the enrolled student have been used to help address this concern. Since this is an elective course and students from outside of social work are enrolled, the inclusion of engagement as a goal helps ensure that all students have some direct exposure to the military culture. 


\section{Discussion and Recommendations}

More efforts to train masters-level students in social work to address the needs of military personnel, veterans, and their families are important to help meet the need for increased levels and improved quality of services for the population, especially given that the troops continue to transition home from Afghanistan and the military is downsizing. Online programs at the graduate level have increased dramatically and this increase can be an advantage for educating social work students about practice with veterans. This course is only a first step and needs to be replicated and evaluated more.

We have not done a formal evaluation, but we have identified some of the course's strengths, weaknesses, challenges and opportunities. One of its strengths is that it has been interdisciplinary, open to both social work graduate students and students from other majors. The diverse background of students from other departments stimulates the online discussion forums and challenges all of the students to see issues from differing perspectives. For example, in a recent online forum, a graduate student from a nonsocial-work department stated he was totally unaware of community-based resources for veterans. This prompted many social work students to provide him with resources.

Although the interdisciplinary nature of the course is a boon, it is also a challenge. Because the needs of veterans cut across many areas, including physical health, mental health, career concerns and social and legal needs, content to prepare social workers must reflect this breadth. Having content that covers all of these areas in one course is difficult, particularly online where contact with the professor is sometimes more difficult to obtain when students need further resources on the breadth of topics. However, using a variety of web-based links and videos as well as the digitized guest lectures from the campus-based class helps provide the diversity of information that is needed. Students are also encouraged to access the instructor to follow up on topics of interest.

Another strength of the course pertains to the strong feelings of both students and accrediting bodies about the importance of content about working with veterans. Students in the online course also reported that they took the course because of their deep interest in working with veterans and realized through taking the course that veterans will be a part of many practice settings in their future careers. This fact has implications for how schools of social work infuse the content on veterans throughout their courses, which could be trying in a profession that already has to respond to many mandates from accrediting bodies.

One of the most important merits of the online course is its focus on the goal of engagement with veterans. This goal of engagement and not just building a reading-based knowledge of veterans is a challenge in an online course. This challenge is what makes the assignments that develop opportunities for engagement important. The veteran interview, service-learning projects, and required attendance at veteran events are all designed with this goal in mind. Achieving this goal takes more planning when students are dispersed geographically, but it still can be done. This goal of engagement also relates to building a commitment among enrolled students to continue to learn about the military culture and its population. The broad nature of assignments designed to build this awareness through engagement with the veteran population also provides diversity in the types of activities offered in an online format. There are many opportunities for future service learning projects that are engaging to the student and beneficial to the military and veteran communities.

This online elective provides only a foundation on military culture and knowledge of service delivery and treatment topics. To build a more in-depth knowledge and skill base would require a followon course on trauma and clinical assessment and treatment issues. Although this is outside the scope of this course, the current elective does lay a foundation and framework for continued learning. This dilemma of how to build more in-depth knowledge has been echoed in other studies of outcomes with similar electives on military social work (Forgey \& Young, 2014). Further research on this issue is needed to examine outcomes and how to build on them in a developmental way. Online efforts can help 
address these issues by laying out an approach to providing more comprehensive training for reaching the military social work advanced practice guidelines developed by CSWE.

Another benefit of this elective course has been that it draws enrollment from veterans from social work as well as from other departments. One observation of note is that veterans who take the course report learning new information. For example, one veteran who recently took a course that he had never considered until taking, proclaimed how it impacted his deployments, service and family. Another veteran stated that she never considered herself to be connected to the veteran community and thus never self-identified as a veteran until she took the course and finally felt a more valued and personal connection to other veterans and also felt "honored." Although these reports are only anecdotal, the instructor has received many comments from veterans taking the online and on-campus course indicating that veterans find this course to be healing in nature. There is a rich opportunity here for research on what contributes to this this possible healing dimension and how to enhance it.

Active-duty military personnel and veterans are transitioning back to their communities and many into civilian life both in the private and public sectors. They bring with them many leadership qualities as well as unique needs that have to be addressed by varied institutions, such as those providing educational, health and mental health services. Social work education must use its recent online endeavors to increase the training and preparation of veteran service providers so that our veterans have access to all of the quality services they have earned. This training and preparation includes establishing cultural competency in working with this population. We have a responsibility to bridge the military-civilian divide and share in this work for our military, veterans and their families. Former Secretary of Defense Robert Gates said that even after a decade of war, for most Americans, the wars and their impact remained "an abstraction" (Gates, 2010). The question is whether social work education will create a vision and take a leadership role in helping the country break through this abstraction in order to prepare a cadre of well-trained, culturally competent veteran service providers for the newest “Great Generation” of veterans.

\section{Acknowledgments}

The work in this article was supported by the Bureau of Health Professions (BHPr), Health Resources and Services Administration (HRSA), and Department of Health and Human Services Administration (DHHS) under grant number HRSA-12-181, Mental and Behavioral Health Education and Training Grants financed by 2012 Prevention and Public Health Funds (PPHF-2012), M01HP25195, Project Stand Up for Veterans, in the amount of \$479,035. 


\section{References}

Abels, P. (2005). The way to distance education. In P. Abels, (Ed.), Distance education in social work: Planning, teaching and learning. New York: Springer.

Allen, I. E., \& Seaman, J. (2014). Grade change - tracking online education in the United States. Babson Survey Research Group \& Quahog Research Group, LLC.

Coll, J. E., \& Weiss, E. L. (2013). Transitioning veterans into civilian life. In A. Rubin, E. L. Weiss, \& J. E. Coll (Eds.), Handbook of military social work (pp. 281-297). New Jersey: John Wiley \& Sons.

Council on Social Work Education. (2010). Advanced social work practice in military social work. Washington, DC: CSWE Press. Retrieved from http://www.cswe.org/File.aspx?id=76078.

Council on Social Work Education. (2011). 2011 statistics on social work education in the United States, Washington, D.C.: CSWE. Retrieved from http://www.cswe.org/CentersInitiatives/DataStatistics/ProgramData/62008.aspx

Council on Social Work Education. (2012). 2012 statistics on social work education in the United States, Washington, D.C.: CSWE. Retrieved from http://www.cswe.org/CentersInitiatives/DataStatistics/ProgramData/68987.aspx

Dao, J. (2012). Veterans Department to increase mental health staffing. New York Times, April 19, 2012. Retrieved from http://www.nytimes.com/2012/04/19/us/veterans-affairs-dept-to-increase-mentalhealth-staffing.html? $\mathrm{r}=0$

Demers, A. (2011). When veterans return: The role of community in reintegration. Journal of Loss and Trauma, 16, 160-179.

DiRamio, D., Ackerman, R., \& Mitchell, R. L. (2008). From combat to campus: Voices of studentveterans. NASPA (National Association of Student Personnel Administrators, Inc.) Journal, 45(1), 73-102.

DiRamio, D., Ackerman, R., \& Mitchell, R. L. (2009). Transitions: Combat veterans as college students. New Directions for Student Services, 126, 5-14.

East, J., LaMendola, W., \& Alter, C. (2014). Distance education and organizational environment. Journal of Social Work Education, 50(1), 19-33.

Forgey, M., \& Young, S. (2014). Increasing military social work knowledge: An evaluation of learning outcomes. Health \& Social Work, 39(1), 7-14.

Franklin, E. (2009). The emerging needs of veterans: A call to action for the social work profession. Health \& Social Work, 34(3), 163-167.

Gates, R. (2010). Lecture at Duke University, delivered on September 29, 2010. Retrieved from http://www.defense.gov/speeches/speech.aspx?speechid=1508

Johnson, O., \& Johnson, I. (2013). Traumatic grief among African American soldiers exposed to combat: Implications for social work education. Journal of Human Behavior and the Social Environment, 23, 726-736.

Lawrence. S., \& Abel, M. (2014). Comparing outcomes of a web-based MSW course to face-to-face class outcomes: Implications for social work education, Social Work Education, 32(6), 762-772.

Luby, C. (2012). Promoting military cultural awareness in an off-post community of behavioral health and social support service providers. Advances in Social Work, 13(1), 67-82.

Military Times Edge Magazine. (2014). Best for vets. Retrieved from http://projects.militarytimes.com/jobs/best-for-vets/2014/colleges/4-year

Newell, J. (2012). Addressing the needs of veterans and military families: A generalist approach. The Journal of Baccalaureate Social Work, 17, 53-68. 
Petrovich, J. (2012). Culturally competent social work practice with veterans: An overview of the U.S. Military. Journal of Human Behavior in the Social Environment, 22, 863-874.

Rubin, A. (2012). Civilian social work with veterans returning from Iraq and Afghanistan: A call to action. Social Work, 57(4), 293-296.

Savitsky, L., Illingworth, M., \& DuLaney, M. (2009). Civilian social work: Serving the military and veteran populations. Social Work, 54(4), 327-339.

Schlossberg, N. K., Waters, E. B., \& Goodman, J. (1995). Counseling adults in transition (2nd ed.). New York: Springer.

Selber, K. (in press). A model for serving this generation of student veterans in universities: Blending supportive services and educational missions. In J. E. Coll \& E. L. Weiss (Eds.), Supporting veterans in higher education: A primer for administrators, faculty, and academic advisors. Chicago, IL: Lyceum Books, Inc.

U.S. Department of Veterans Affairs. (2014). National Center for Veterans Analysis and Services. Retrieved from http://www.va.gov/vetdata/Maps.asp

Whitworth, J., Herzog, J., \& Scott, D. (2012). Problem-based learning strategies for teaching military social work practice behavior: Review and evaluation. Advances in Social Work, 13(1), 112-131. 